\title{
A PESQUISA CIENTÍFICA NO ENSINO MÉDIO: UMA PROPOSTA DE ENSINO POR INVESTIGAÇÃO SOBRE O CONTEÚDO "ARTRÓPODOS PeÇonhentos"
}

\author{
SCIENTIFIC RESEARCH IN HIGH SCHOOL: A PROPOSAL FOR INQUIRY-BASED TEACHING \\ ON THE CONTENT "VENOMOUS ARTHROPODS"
}

LA INVESTIGACIÓN CIENTÍFICA EN EL BACHILLERATO: UNA PROPUESTA DE ENSEÑANZA POR MEDIO DE LA INVESTIGACIÓN SOBRE EL CONTENIDO “ARTRÓPODOS VENENOSOS”

\section{Dilene de Lima Pantaleão (in memoriam) \\ (iD) 9 \\ Mestra em Ensino de Biologia (UFPE-CAV) \\ Professora de Rede Estadual de Ensino de Pernambuco \\ dilene.pantaleao@ufpe.br (indisponível)}

\section{Simão Dias Vasconcelos (iD) 9}

$\mathrm{PhD}$ em Zoologia (University of Oxford)

Professor na Universidade Federal de Pernambuco

Mestrado Profissional em Ensino de Biologia

simao.vasconcelosfo@ufpe.br

\begin{abstract}
Resumo
O ensino por investigação baseia-se na construção de competências associadas à pesquisa científica, com definição de problema, registro de dados, análise e interpretação de resultados, a partir da realidade do estudante. Relatamos aqui um estudo desenvolvido no ensino médio de uma escola pública do sertão pernambucano, por meio da construção e validação de uma sequência de ensino investigativa (SEI), tendo como tema gerador "Artrópodos Peçonhentos". Os estudantes vivenciaram etapas de uma pesquisa científica, desde a elaboração do projeto até a produção textual e apresentação pública dos resultados. Visando nortear o docente sintetizamos a SEI em seis etapas: i) Apresentação do projeto e contextualização teórica, ii) Construção de competências em pesquisa, iii) Elaboração dos Planos de Pesquisa, iv) Execução da pesquisa, v) Produção do relatório científico, e vi) Socialização do conhecimento. Os estudantes realizaram pesquisa bibliográfica, documental, e também levantamento, por meio de entrevista com a comunidade extraescolar. Consideramos a SEI exitosa, por ter promovido o protagonismo e a aproximação discentes com a apropriação de saberes sobre artrópodos peçonhentos pela população e por profissionais especializados, contribuindo no fomento a competências previstas para o ensino médio.
\end{abstract}

Palavras-chave: Ensino de Biologia. Pernambuco. Metodologia Científica. Escola Pública. Escorpionismo.

Recebido em: 9 de maio de 2021.

Aprovado em: 19 de julho de 2021.

Como citar esse artigo (ABNT):

PANTALEÃO, Dilene de Lima; VASCONCELOS, Simão Dias. A pesquisa científica no ensino médio: Uma proposta de ensino por investigação sobre o conteúdo "Artrópodos Peçonhentos". Revista Prática Docente, v. 6, n. 2, e055, 2021. http://doi.org/10.23926/RPD.2021.v6.n2.e055.id1175 


\section{Abstract}

Inquiry-based teaching is based on the construction of skills associated with scientific research, with problem definition, data recording, analysis and interpretation of results, focused on the student's reality. We report here a study developed in the high school of a public school in the countryside of Pernambuco, through the construction and validation of an investigative teaching sequence (ITS), with the theme "Venomous Arthropods". The students experienced stages of scientific research, from the elaboration of the project to the textual production and public presentation of the results. In order to guide the teacher, we summarized the ITS in six stages: i) Presentation of the project and theoretical context, ii) Construction of research skills, iii) Elaboration of Research Plans, iv) Execution of research, v) Production of the scientific report, and vi) Socialization of knowledge. The students carried out bibliographic and documentary research, as well as a survey, through an interview with the out-of-school community. We consider the ITS to have been successful, because it promoted the protagonism and the approach of students with the appropriation of knowledge about venomous arthropods by the population and by specialized professionals, contributing to the promotion of competences designed for high school.

Keywords: Biology Teaching. Pernambuco. Scientific Methodology. Public School. Scorpionism.

\section{Resumen}

La docencia investigadora se basa en la construcción de habilidades asociadas a la investigación científica, con definición de problemas, registro de datos, análisis e interpretación de resultados, a partir de la realidad del alumno. Presentamos aquí un estudio desarrollado en la escuela secundaria de una escuela pública en el interior de Pernambuco, a través de la construcción y validación de una secuencia de enseñanza investigativa (SEI), con el tema "Artrópodos venenosos". Los estudiantes vivieron etapas de investigación científica, desde el diseño del proyecto hasta la producción textual y presentación pública de los resultados. Con el fin de orientar al docente, sintetizamos la SEI en seis etapas: i) Presentación del proyecto y contexto teórico, ii) Construcción de habilidades investigativas, iii) Elaboración de Planes de Investigación, iv) Ejecución de la investigación, v) Producción del informe científico, y vi) Socialización del conocimiento. Los estudiantes realizaron una investigación bibliográfica y documental, así como una entrevista con la comunidad extraescolar. Consideramos que la SEI fue exitosa, porque promovió el protagonismo y el acercamiento de los estudiantes con la apropiación de conocimientos sobre artrópodos venenosos por parte de la población y de profesionales especializados, contribuyendo a la promoción de competencias previstas para el bachillerato.

Palabras clave: Enseñanza de Biología. Pernambuco. Metodología Científica. Escuela pública. Escorpionismo. 


\section{INTRODUÇÃ̃o}

\subsection{DESAFIOS DO ENSINO POR INVESTIGAÇÃO}

Em um mundo de desafios teóricos e metodológicos, ensinar sobre Ciência - e como fazer Ciência - adquire novas complexidades. O ensino médio, em particular, enfrenta o compromisso de apresentar um conteúdo vasto e desafiador, ao mesmo tempo em que tem como uma de suas competências gerais

Exercitar a curiosidade intelectual e recorrer à abordagem própria das ciências, incluindo a investigação, a reflexão, a análise crítica, a imaginação e a criatividade, para investigar causas, elaborar e testar hipóteses, formular e resolver problemas e criar soluções [...] com base nos conhecimentos das diferentes áreas (BRASIL, 2018, p.9).

A promoção destas competências requer uma ressignificação da prática docente, substituindo a pedagogia expositiva, centrada no professor, por abordagens metodológicas centradas no protagonismo discente, viabilizando oportunidades de definir problemas, elaborar hipóteses, pesquisar, construir e reconstruir conhecimentos. Esta síntese aplica-se a um conjunto de abordagens e procedimentos caracterizados como ensino por investigação.

No ensino por investigação, o professor assume papel de mediador, alterando a dinâmica das aulas, o que implica estimular no estudante o questionamento, o planejamento, a análise de dados, a elaboração de explicações com base nas evidências e as competências de comunicação (AZEVEDO, 2004). O ensino por investigação instiga o aprendiz a descobrir o fato gerador de um fenômeno, provocando sua curiosidade para descobrir soluções por meio da pesquisa preferencialmente a partir de um problema de sua própria realidade, visando à construção do conhecimento. Esse processo "exige que o aluno tenha discernimento para optar e escolher as possíveis soluções para a problemática levantada" (BEHRENS, 2006, p.42). Trata-se de uma opção desafiadora, pois

Pesquisas nas áreas de Educação e Psicologia sugerem que as habilidades de investigação científica dos alunos não são estáticas; dependem de uma variedade de fatores cognitivos e afetivos. Esses fatores incluem interesse e motivação em ciências, compreensão epistemológica e do valor do processo científico, familiaridade com o domínio de investigação e o contexto da atividade, suporte de atividades de investigação e habilidades de comunicação. (...) os alunos demonstram autonomia em fazer escolhas, autorregulação e oportunidades de trabalhar em projetos de seu interesse, recursos que podem aumentar a motivação (SADEH; ZION, 2011, p. 833).

Esta abordagem incentiva aprender de forma autônoma e participativa, a partir de problemas e situações reais, fazendo com que os estudantes produzam conhecimento por meio de desafios e solução de problemas (REHOREK, 2004). Orientados pelo professor, o discente 
precisa explorar as soluções possíveis dentro de um contexto específico, utilizando-se de diversos recursos. Vale salientar que a investigação científica é uma atividade humana e social que incorpora os valores, princípios e interesses da época, guiando não só a particularidade do problema, mas também o método de análise (SLONGO; DELIZOICOV, 2006).

Segundo Krasilchik (2005, p.87), uma atividade interessante e desafiadora

permite relacionar os fatos às soluções de problemas, dando-lhes oportunidades de identificar questões para investigação, elaborarem hipóteses e planejar experimentos para testá-las, organizar e interpretar dados e, a partir deles, fazer generalizações e inferências, ao permitir que os alunos aliem a teoria à prática, o que contribui para formação de profissionais completos que o mundo de trabalho procura.

O estímulo à construção de explicações sobre os fenômenos é um eixo indispensável do ensino por investigação, pois como afirmam Sasseron e Carvalho (2008, p.339), o ensino de Ciências deve

[...] desenvolver atividades que (...) permitam as argumentações entre alunos e professor em diferentes momentos da investigação e do trabalho envolvido. Com problemas investigativos e questões reflexivas, esperamos que os alunos teçam hipóteses e planos que auxiliem na resolução, bem como discutam sobre as ideias levantadas e outras questões controversas que possam surgir.

\subsection{SEQUÊNCIAS DE ENSINO INVESTIGATIVAS}

Adotar o ensino por investigação instiga o docente a organizar as atividades em uma sequência lógica de descobertas, fruto de um rigoroso planejamento. Para Zabala (1998, p.18), sequências didáticas (SD) são atividades ordenadas e articuladas para a "realização de certos objetivos educacionais, que têm um princípio e um fim conhecidos, tanto pelos professores como pelos estudantes". Nesse sentido, uma SD deve favorecer a autonomia e o protagonismo estudantil sobre todas as etapas e metodologias aplicadas no desenvolvimento deste trabalho, para que o conhecimento tenha sentido ao aprendiz, ou seja, que possa ser utilizado na compreensão da realidade. Logo, uma SD pode ser entendida como um conjunto de atividades sequenciadas e organizadas de maneira sistemática, adequadas à realidade dos estudantes, objetivando um favorecimento na mudança e na promoção dos alunos ao domínio dos conteúdos propostos (GONÇALVES; BARROS, 2010).

Carvalho (2013), baseada em alguns teóricos construtivistas, a exemplo de Piaget, e sociointeracionistas como Vygotsky, Lemke, Driver e Lawson, propõe incorporar às SD um rigoroso planejamento de atividades investigativas, transformando-se em intervenções mais motivadoras e significativas para estudantes e professores. A autora propôs o termo Sequências de Ensino Investigativas (SEI), que visam não somente à observação dos fenômenos - papel 
contemplativo - ou apenas a reprodução dos passos de um experimento - papel manipulativo, mas, sim, oportunizar questionamentos, testes de hipóteses, trocas de informações e sistematizações de ideias (CARVALHO, 2013).

É importante ressaltar que Carvalho (2013) não propõe um modelo de SEI com etapas fixas e rígidas, mas sim, etapas essenciais, intrinsicamente pertinentes a toda investigação científica, e que basicamente envolvem

um Problema, acompanhado de uma pergunta simples, objetiva, que possa desencadear ações nos alunos; em seguida, busca-se a Familiarização e a Solução do Problema proposto com Discussões diversas, seguida de Reflexões sobre as relações de causa e efeito; Contextualização do problema relacionando-o com o cotidiano e, por fim, o Registro que apresenta como chegou a solução para o problema deve ser realizado na forma de texto e/ou desenho (CARVALHO, 2013, p.9).

Ou seja, as práticas que visam ao protagonismo estudantil devem estimular sua autonomia, motivando-o a buscar conhecimentos de forma independente, onde o professor apenas fará a mediação do processo de ensino aprendizagem (SINGER, 2017). Além disso o aluno que vivencia os métodos ativos desenvolve maior confiança em si mesmo, melhora a expressividade oral e escrita e aprende a trabalhar em grupo (REHOREK, 2004).

A realidade das escolas públicas na Região Nordeste nem sempre oferece oportunidades para o docente desenvolver atividades investigativas, seja por falta de infraestrutura, dificuldades na formação docente ou na motivação dos estudantes, os quais possuem baixa familiarização com procedimentos de pesquisa. Experimentos, projetos investigativos e Feiras de Ciências não estão entre as práticas pedagógicas mais comumente adotadas por professores do ensino básico da rede pública (VASCONCELOS; LIMA, 2020). Entretanto, tão ou mais crítica do que a ausência de infraestrutura, é a escassez de propostas, recursos e orientações metodológicos acessíveis para o professor com limitada experiência em investigação.

Não há dúvida de que o ensino de investigação em aulas de ciências pode criar dilemas para professores que muitas vezes se esforçam para fornecer experiências científicas de investigação suficientes, dadas as limitações de tempo, o currículo superdimensionado e a falta de experiência dos alunos com a aprendizagem de investigação (GILLIES; NICHOLS, 2014, p.3, tradução dos autores).

Iniciativas recentes, como a criação do Mestrado Profissional em Ensino de Biologia, em 2017, desenvolvido em rede, com sede na Universidade Federal de Minas Gerais (UFMG), têm buscado preencher esta lacuna, fomentando a criação e validação de intervenções didáticas de cunho investigativo a serem socializadas com professores de todo o país. Destinado para docentes da rede pública de ensino médio, prioriza a construção e a validação de intervenções 
didáticas contextualizadas e multidisciplinares, com ênfase no protagonismo discente. A pesquisa apresentada neste artigo é fruto de uma dissertação de mestrado deste programa.

Considerando estes argumentos e a realidade local da escola alvo deste estudo, em Petrolina, fomos motivados a abordar o conteúdo "Artrópodos Peçonhentos”, devido aos alarmantes índices de acidentes escorpiônicos em Pernambuco, especialmente no Vale do Submédio São Francisco.

Segundo o Sistema de Informação de Agravos de Notificação-SINAN foram registrados 597 acidentes com animais peçonhentos em Petrolina (PE) em 2019, sendo 346 com escorpiões, 151 com abelhas e 30 com aranhas, distribuídos em diversos bairros, incluindo aqueles situados próximos à escola (BRASIL, 2020). O envenenamento provocado pela picada de escorpião faz parte da Lista de Notificação Compulsória, ou seja, as unidades de saúde devem informar os casos aos serviços de vigilância e controle de zoonoses, para medidas de manejo.

Escolhemos, desta forma, o tema "Artrópodos Peçonhentos" (AP) porque, além de sua importância prática, o tópico permite uma abordagem interdisciplinar baseada em diversos conteúdos da Biologia do ensino médio, como Biodiversidade, Saúde, Toxicologia, Zoologia, Ecologia, Fisiologia, Educação Ambiental, entre outros.

Relatos de experiência sobre metodologias de ensino, como as sequências didáticas, são oportunidades extraordinárias para compartilhar iniciativas exitosas, socializar conhecimento prático construído em sala de aula e despertar o interesse de professores-pesquisadores sobre novas abordagens e temas. Mais do que isso, a construção e validação de uma sequência de ensino é também objeto de pesquisa e amadurecimento profissional para o docente que a propõe, alertando sobre dificuldades e desafios. Relatos de professores de escolas públicas que fazem pesquisa apontam para vários benefícios: o docente sente-se mais confortável com as inovações teóricas e tecnológicas de sua área, melhora sua prática pedagógica e compreende melhor como as descobertas científicas foram produzidas historicamente (ULLA, 2018).

Considerando estes argumentos, este trabalho relata a criação e validação de uma SEI desenvolvida em uma escola pública do sertão pernambucano, tendo como eixo norteador o conteúdo AP. Especificamente, descrevemos uma experiência que visou estimular a pesquisa e a construção de trabalhos científicos no desenvolvimento da aprendizagem; introduzir elementos da investigação científica na prática docente; fomentar o protagonismo discente na busca de informações e na construção do arcabouço teórico-metodológico; aproximar o 
estudante da realidade profissional extraclasse, e estimular competências de produção textual e oralidade, na forma de apresentações e relatos científicos.

\section{ConteXtualização E METOdologia}

A intervenção didática apropriou-se de ferramentas da pesquisa qualitativa, combinando procedimentos da pesquisa-ação, levantamento, pesquisa bibliográfica, pesquisa documental e observação participante e estudo de caso (GRAY, 2012). Por sua natureza descritiva e exploratória, a experiência prioriza o entendimento dos fenômenos estudados sem priorizar os dados numéricos.

A pesquisa foi realizada em 2019, antes da pandemia de Covid-19, em uma escola de ensino regular da rede estadual de Pernambuco situada na zona urbana de Petrolina-PE, que oferece Ensino Fundamental, Ensino Médio e Educação de Jovens e Adultos. A escola apresenta público diversificado, sendo a maioria de baixa renda, oriunda do próprio bairro e de bairros circunvizinhos. $\mathrm{O}$ estudo foi desenvolvido com uma turma do $2^{\circ}$ ano do ensino médio com 37 estudantes de 15 a 19 anos, selecionada devido ao fato de o conteúdo (Artrópodos) ser abordado com maior ênfase nesta série.

Para motivar os alunos, a professora apresentou o projeto, explicando sobre a importância do tema gerador e a metodologia escolhida. Após a explanação, os estudantes tiraram suas dúvidas em relação ao seu envolvimento no projeto e decidiram participar espontaneamente. Optamos por manter o anonimato dos participantes.

\section{CONSTRUÇÃO DA SEQUÊNCIA DE ENSINO INVESTIGATIVA}

A SEI foi planejada para ser desenvolvida em 15 horas-aulas de 50 minutos, além das atividades extraclasse, e organizada em seis etapas, descritas a seguir.

\subsection{Etapa 1 - Apresentação do Projeto e ConteXtualização Teórica}

A etapa 1 iniciou-se com o mapeamento dos saberes iniciais e percepções dos discentes sobre AP, exemplos e importância destes animais, e atitude em casos de acidentes, e compreendeu 1 hora/aula. A partir destes saberes, a docente propôs uma aula expositiva dialogada, ocupando 3 horas/aula. Finalizamos com uma roda de conversa apresentando e discutindo o problema dos acidentes causados por AP em Petrolina, durante 1 hora/aula.

Como ponto de partida para aprofundamento teórico, selecionamos textos, artigos de divulgação científica, monografias e manuais sobre características, reprodução e identificação dos artrópodos que poderiam causar acidentes ao homem por meio da inoculação de veneno e 
os disponibilizamos no formato PDF para os estudantes participantes (Apêndice A). Todo o material foi impresso e distribuído a cada grupo, porque alguns estudantes não dispunham de acesso frequente à internet. Esses textos apresentam linguagem acessível ao nível dos jovens e foram utilizados como fonte inicial de pesquisa pelos estudantes durante a execução do projeto.

Os discentes foram orientados a indicar pelo menos mais três referências e a identificar a credibilidade das fontes usadas na revisão bibliográfica. Esta etapa evidenciou a importância da leitura e estimulou a curiosidade dos discentes na busca por mais fontes de informação.

\subsection{ETAPA 2 - CONSTRUÇÃO DE COMPETÊNCIAS EM PESQUISA CIENTÍFICA}

Os discentes participaram de oficinas sobre o método científico, em 4 horas/aula, contemplando atividades como a dinâmica da "caixa misteriosa" para levantar hipóteses sobre qual objeto estaria contido na caixa, de acordo com o peso, o barulho e outras "pistas"; e por uma atividade de interpretação de tabelas e gráficos, para familiarizá-los com relações de causa e efeito entre variáveis e com recursos não textuais.

Os estudantes foram orientados a realizar, extraclasse, o curso on-line gratuito Metodologia da Pesquisa e Orientação de Projetos de Iniciação Científica, da Plataforma Ápice/FEBRACE (Feira Brasileira de Ciências e Engenharia) (https://apice.febrace.org.br/). O curso de 30 horas apresenta atividades interativas e linguagem adequada ao nível dos estudantes e oferece o aporte necessário para o passo-a-passo da construção e desenvolvimento de um projeto de pesquisa, em 14 módulos.

\subsection{Etapa 3 - Elaboração dos Planos de Pesquisa (PP)}

Após o Curso, os estudantes iniciaram a construção dos PP, seguindo o modelo da Febrace (Apêndice B). Organizados em cinco grupos formados espontaneamente, os estudantes foram motivados a levantar as questões que gostariam de estudar e elaborar objetivos a serem alcançados durante sua execução. A elaboração dos PP foi iniciada em sala de aula utilizando 2 horas/aula e concluída no contraturno, sob supervisão da professora.

Para a construção do PP, as equipes deveriam delimitar quais atores da comunidade extraescolar seriam os colaboradores da pesquisa, a fim de promover o diálogo entre o conteúdo das aulas e os saberes externos e a partir desse diálogo construir o seu aprendizado. As equipes foram estimuladas a construir um "Diário de Bordo", mantido na escola, de formato livre, com sugestões de entrada diária de ideias, informações e avanços, sem caráter avaliatório. 


\subsection{ETAPA 4 - DESENVOLVIMENTO DA ATIVIDADE INVESTIGATIVA}

As equipes foram instigadas a realizar coleta de dados e informações junto à população e a alguns órgãos envolvidos no estudo, prevenção e controle de acidentes por AP para contextualizar a aprendizagem, como hospitais, instituições de ensino e pesquisa, Corpo de Bombeiros. Os estudantes saíram da escola para os locais onde seriam desenvolvidas as pesquisas de campo, por meio de pesquisa documental e/ou levantamento (entrevistas semiestruturadas). O transporte e a segurança ficaram a cargo da docente, que obteve as autorizações e o apoio necessários.

\subsection{ETAPA 5 - ELABORAÇÃo dO RELATÓRIO CIENTÍFICO}

Após a coleta de dados, os estudantes foram orientados a analisar as variáveis mensuradas, discutir os resultados e a redigir o relatório científico (RC) seguindo o modelo da Febrace (Apêndice C). A produção do RC teve como objetivo fomentar competências de redação acadêmica e de argumentação sobre os resultados da pesquisa e a construção de conclusões sobre a temática. Os critérios de avaliação, previamente divulgados, incluíram aspectos da produção textual, como correção científica e formatação (Apêndice D).

\subsection{ETAPA 6 - SOCIALIZAÇÃO DO CONHECIMENTO}

Os estudantes foram estimulados a produzir um recurso frequentemente utilizado em eventos científicos - pôster, para apresentar, de forma sintetizada, o percurso e as principais descobertas da pesquisa seguindo um modelo básico (Título, Autores, Nome da Escola, Introdução, Metodologia, Resultados, Discussão e Referências). Os pôsteres foram destinados à apresentação para os demais colegas de turma e avaliados de acordo com critérios previamente divulgados (Apêndice D). A impressão ficou a cargo da docente.

\section{VALIDAÇÃO DA SEQUÊNCIA DE ENSINO INVESTIGATIVA}

A sequência didática foi cumprida, no prazo estabelecido e com os objetivos alcançados. Descrevemos e discutimos de forma sintetizada os resultados a seguir (Figura 1). 
Figura 1 - Etapas da Sequência de Ensino Investigativa

\section{SEQUÊNCIA DE ENSINO INVESTIGATIVA}
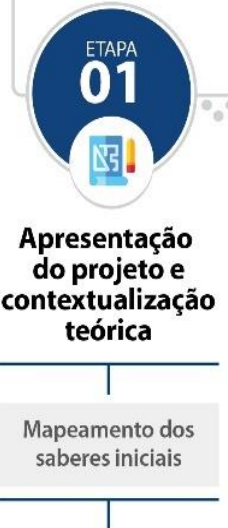

Exposição dialogada

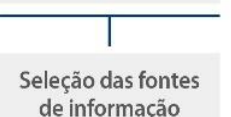

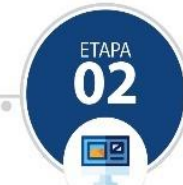

Construção de competências em
pesquisa científica

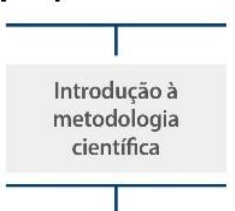

Curso on-line de Iniciação Científica

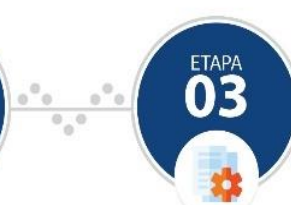

Elaboração dos Planos de Pesquisa

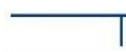

Escolha dos temas

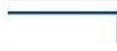

Seleção do público extraescolar

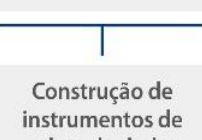

coleta de dados

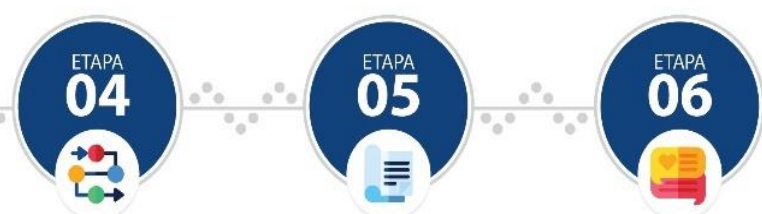

Desenvolvimento da Atividade Investigativa

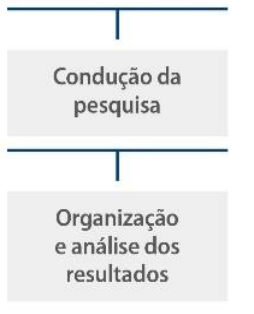

Elaboração do relatório científico
Socialização do conhecimento

Fonte: Elaborado pelos autores.

\subsection{Etapa 1 - Apresentação do Projeto e ConteXtualização Teórica}

No mapeamento dos saberes prévios, a maioria dos discentes categorizou os AP como animais "perigosos $(86,5 \%)$, mas parte da turma afirmou que estes animais não possuem veneno (54,0\%). Curiosamente, 73,0\% citaram corretamente como exemplos de AP: aranha, escorpião e abelha; porém, reforçando a construção do conceito de "peçonhento" como "perigoso", 24,7\% citaram onça, gavião, leão e tigre como animais peçonhentos. As respostas incorretas foram devidamente esclarecidas. Positivamente, todos consideraram importante estudar os AP e 89,2\% reconhecem a importância destes animais no equilíbrio ecológico. A maioria (70,3\%) afirmou que a vítima de acidente deveria ser conduzida ao hospital; no entanto, 16,2\% recomendaram procedimentos caseiros (chás, infusões, etc.) característicos da medicina popular, evidenciando uma prática comum em comunidades de áreas rurais, que é o caso da maior parte dos estudantes da escola.

$\mathrm{Na}$ exposição dialogada, a professora abordou aspectos da diversidade, características, comportamento, função do veneno e importância dos AP. Os estudantes demonstraram interesse sobre o tema, expressando a ressignificação de alguns conceitos, como: "diferença entre artrópodos venenosos e peçonhentos", “importância positiva dos AP” entre outros.

$\mathrm{Na}$ aula seguinte, na roda de conversa sobre AP no contexto local, os estudantes expressaram seus saberes sobre a crescente frequência de escorpiões e aranhas em suas residências, e questionaram os motivos dessa ocorrência. Instigamos os estudantes a questionar 
se esta frequência estaria associada a alterações ambientais devido à urbanização desorganizada que pode favorecer as condições necessárias à presença destes animais nas cidades, o que, somado a práticas sanitárias deficientes e desconhecimento populacional de práticas de cuidado e prevenção, pode ser intensificado.

Nesta etapa, discutimos sobre os resultados da revisão bibliográfica, na qual os estudantes realizaram leitura de textos indicados pela professora e por iniciativa própria, incluindo livros, revistas, dissertações, reportagens e relatórios de órgãos públicos sobre acidentes provocados por artrópodos. Os discentes expressaram certa dificuldade na compreensão dos textos mais elaborados/avançados, como artigos e dissertações.

\subsection{ETAPA 2 - CONSTRUÇÃO DE COMPETÊNCIAS EM PESQUISA CIENTÍFICA}

Ao receber modelos de tabelas e gráficos para interpretar, os estudantes puderam solucionar dúvidas sobre apresentação de dados. A maioria dos estudantes $(81,1 \%)$ relatou ter compreendido como utilizar esses elementos, e a atividade foi bem sucedida no objetivo de aproximar os estudantes de algumas etapas do método científico.

O curso Metodologia da Pesquisa e Orientação de Projetos de Iniciação Científica mostrou-se uma ferramenta atrativa para a construção de competências necessárias para a execução da pesquisa. A maioria dos estudantes (59,5\%) utilizou celulares e os demais $(40,5 \%)$ acessaram a plataforma utilizando os notebooks disponibilizados pela escola. Os estudantes contaram com a mediação da professora para dirimir eventuais dúvidas durante o curso e ao final, fizeram a avaliação on-line para obter a certificação. Os discentes afirmaram que a quantidade de regras, métodos e detalhes de como produzir um texto científico tornaram alguns módulos mais difíceis. Após a superação de dificuldades, os estudantes demonstraram satisfação com a aprovação ao final do curso, levando o certificado para a escola e mostrando aos colegas.

\subsection{Etapa 3 - Elaboração dos Planos de Pesquisa (PP)}

As equipes elaboraram o plano de pesquisa para investigar os acidentes causados por artrópodos em Petrolina, seguindo orientações prévias (Quadro 1). Sob esta perspectiva, os estudantes tiveram autonomia na escolha do título e definição de aspectos da metodologia a ser utilizada, como o roteiro das entrevistas, sendo orientados pela professora que disponibilizou horários de atendimento para solucionar dúvidas. 
Quadro 1 - Títulos dos Planos de Pesquisa sobre “Artrópodos Peçonhentos”, envolvimento da comunidade externa, tópicos e especificidades de cada equipe

\begin{tabular}{|c|c|c|c|c|c|}
\hline Equipe & Título & $\begin{array}{c}\text { Fonte externa } \\
\text { de } \\
\text { conhecimento }\end{array}$ & $\begin{array}{c}\text { Local } \\
\text { explorado na } \\
\text { pesquisa } \\
\end{array}$ & $\begin{array}{c}\text { Eixo } \\
\text { diferencial }\end{array}$ & Especificidades \\
\hline I & $\begin{array}{c}\text { Artrópodos } \\
\text { Peçonhentos: } \\
\text { conhecendo para } \\
\text { adotar medidas de } \\
\text { prevenção }\end{array}$ & $\begin{array}{l}\text { Profissionais } \\
\text { envolvidos no } \\
\text { manejo de AP }\end{array}$ & $\begin{array}{c}4^{\circ} \\
\text { Grupamento } \\
\text { de Bombeiros } \\
\text { Petrolina }\end{array}$ & $\begin{array}{l}\text { Saúde \& } \\
\text { Ecologia }\end{array}$ & $\begin{array}{c}\text { Manejo, prevenção e } \\
\text { controle de AP em } \\
\text { Petrolina. Ocorrência e } \\
\text { tipos mais frequentes de } \\
\text { acidentes }\end{array}$ \\
\hline II & $\begin{array}{c}\text { Artrópodos } \\
\text { Peçonhentos: } \\
\text { prevenção, } \\
\text { conscientização e } \\
\text { orientação }\end{array}$ & $\begin{array}{l}\text { Profissionais } \\
\text { envolvidos na } \\
\text { saúde humana } \\
\text { e animal }\end{array}$ & $\begin{array}{l}\text { Centro de } \\
\text { Zoonoses de } \\
\text { Petrolina }\end{array}$ & $\begin{array}{c}\text { Epidemiologia } \\
\& \text { Zoologia }\end{array}$ & $\begin{array}{l}\text { Reconhecimento das } \\
\text { espécies de AP da } \\
\text { região. Comportamento } \\
\text { dos animais, veneno } \\
\text { produzido. }\end{array}$ \\
\hline III & $\begin{array}{l}\text { Acidentes causados } \\
\text { por artrópodos } \\
\text { peçonhentos no } \\
\text { município de } \\
\text { Petrolina }\end{array}$ & $\begin{array}{c}\text { Profissionais } \\
\text { envolvidos no } \\
\text { estudo e } \\
\text { conservação de } \\
\text { AP } \\
\end{array}$ & $\begin{array}{c}\text { Projeto } \\
\text { Cemafauna } \\
\text { da UNIVASF }\end{array}$ & $\begin{array}{l}\text { Ecologia \& } \\
\text { Conservação }\end{array}$ & $\begin{array}{l}\text { Diversidade, habitat, } \\
\text { hábitos, importância } \\
\text { ecológica, relações } \\
\text { tróficas. }\end{array}$ \\
\hline IV & $\begin{array}{l}\text { Percepção da } \\
\text { população urbana } \\
\text { sobre acidentes } \\
\text { causados por AP } \\
\end{array}$ & $\begin{array}{c}\text { Habitantes da } \\
\text { zona urbana }\end{array}$ & $\begin{array}{l}\text { Bairros da } \\
\text { zona urbana } \\
\text { de Petrolina }\end{array}$ & $\begin{array}{c}\text { Etnozoologia } \\
\text { \& Educação } \\
\text { Ambiental }\end{array}$ & $\begin{array}{l}\text { Conhecimento popular } \\
\text { sobre acidentes, } \\
\text { atitudes sobre medidas } \\
\text { profiláticas e tratamento }\end{array}$ \\
\hline V & $\begin{array}{c}\text { Percepção da } \\
\text { população rural } \\
\text { sobre acidentes } \\
\text { causados por AP }\end{array}$ & $\begin{array}{c}\text { Habitantes da } \\
\text { zona rural }\end{array}$ & $\begin{array}{l}\text { Bairros da } \\
\text { zona rural de } \\
\text { Petrolina }\end{array}$ & $\begin{array}{c}\text { Etnozoologia } \\
\text { \& Educação } \\
\text { Ambiental }\end{array}$ & Similar a Equipe IV \\
\hline
\end{tabular}

$\mathrm{Na}$ avaliação conduzida pela professora, três PP conseguiram classificação "muito boa" em todos os critérios pois produziram textos objetivos, bem redigidos, com poucos erros ortográficos e que atendiam às normas propostas (Apêndice B). Duas equipes tiveram certa dificuldade para escrever seus planos provavelmente devido à baixa familiarização com a redação científica.

Quadro 2 - Avaliação dos produtos das etapas da SEI sobre Artrópodos Peçonhentos

\begin{tabular}{|c|c|c|c|c|c|}
\hline & $\begin{array}{c}\text { Equipe } \\
\text { I }\end{array}$ & $\begin{array}{c}\text { Equipe } \\
\text { II }\end{array}$ & $\begin{array}{c}\text { Equipe } \\
\text { III }\end{array}$ & $\begin{array}{l}\text { Equipe } \\
\text { IV }\end{array}$ & $\begin{array}{c}\text { Equipe } \\
\text { V }\end{array}$ \\
\hline \multicolumn{6}{|c|}{ Avaliação dos planos de pesquisa } \\
\hline Organização textual & 棘) & 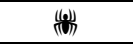 & 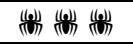 & 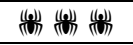 & 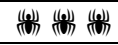 \\
\hline Adequação às normas de produção textual & 海) & 颗) & 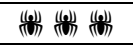 & 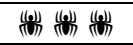 & 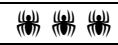 \\
\hline Contextualização & 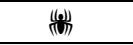 & 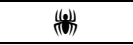 & 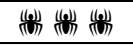 & 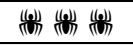 & 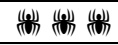 \\
\hline \multicolumn{6}{|c|}{ Avaliação dos relatórios científicos } \\
\hline Organização textual & 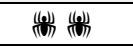 & 颗制 & 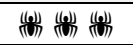 & 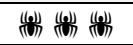 & 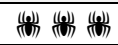 \\
\hline Adequação às normas de produção textual & 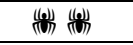 & 精精 & 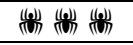 & 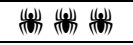 & 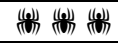 \\
\hline Contextualização & 徏棘 & 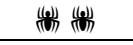 & 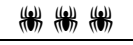 & 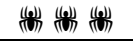 & 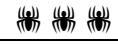 \\
\hline Qualidade de Figuras e Tabelas & 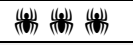 & 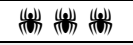 & 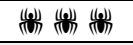 & 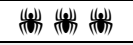 & 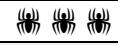 \\
\hline \multicolumn{6}{|c|}{ Avaliação da apresentação dos pôsteres } \\
\hline Clareza & (4) (4) & 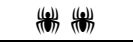 & 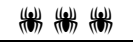 & 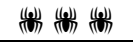 & 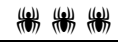 \\
\hline Domínio do conteúdo & 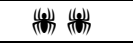 & 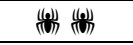 & (精) 精) 精) & (精) 精) 精) & 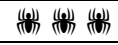 \\
\hline Postura & 颗 & 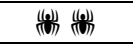 & 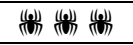 & 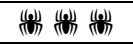 & 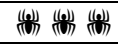 \\
\hline Organização do pôster & 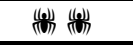 & 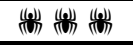 & 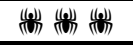 & 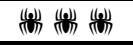 & 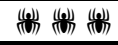 \\
\hline
\end{tabular}

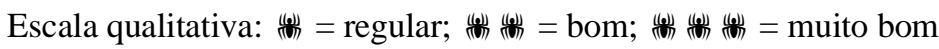




\subsection{ETAPA 4 - DESENVOLVIMENTO DA ATIVIDADE INVESTIGATIVA}

Após a validação dos PP, os estudantes passaram para a etapa de coleta de dados por meio de pesquisa documental e de levantamento (aplicação de entrevistas). Acompanhadas pela professora, as cinco equipes realizaram coleta de dados sobre acidentes com artrópodos na região de Petrolina em ambientes externos à escola. A escolha desses locais de estudo, sugeridos pelos próprios estudantes a partir de opções realistas sugeridas pela docente em um brainstorm, teve a finalidade de integrar o conhecimento acadêmico, do livro didático, ao conhecimento experiencial.

Em equipe, os estudantes realizaram coleta de dados e informações em órgãos envolvidos no estudo, prevenção e controle dos artrópodos junto a profissionais de diversas áreas, para que pudessem ampliar o conhecimento formal, e também com moradores da zona rural e urbana do munícipio, para identificação dos saberes populares. Os temas foram assim distribuídos: Corpo de Bombeiros de Petrolina (Equipe I); Centro de Zoonoses de Petrolina (equipe II); Projeto Cemafauna da Universidade Federal do Vale do São Francisco (Univasf) (Equipe III); população da zona urbana (Equipe IV); e população da zona rural (Equipe V). Por meio da pesquisa, os alunos identificaram os artrópodos peçonhentos mais frequentemente envolvidos em acidentes em Petrolina e puderam testar hipóteses sobre a relação entre o crescimento da população, a modificação ambiental e o aumento dos casos, a importância dos artrópodos no equilíbrio ecológico e para a medicina, e também valorizar saberes populares sobre a prevenção de acidentes. As hipóteses foram elaboradas de forma simples, condizentes com o nível dos estudantes e com a complexidade da pesquisa. Algumas hipóteses foram comuns a mais de uma equipe e foram construídas de forma a aceitar ou rejeitar proposições como "quais os AP mais frequentemente envolvidos em acidentes". "os ambientes onde os AP são encontrados com mais frequência", "as partes do corpo mais comumente afetadas no acidente", e "o nível de conhecimento da população sobre AP na zona rural e urbana".

A Equipe I entrevistou um oficial do Corpo de Bombeiros de Petrolina que expôs os casos de acidentes que a corporação atende na região e relatou sua rotina na remoção de colmeias de abelhas e marimbondos localizados em árvores e praças da cidade e orientou sobre maneiras de prevenção contra acidentes. Os estudantes realizaram questionamentos contextualizados a exemplo de como proceder diante de contato com abelhas, quais os primeiros socorros aplicados à vítima do acidente, entre outros aspectos. 
No PP da Equipe II, a veterinária do Centro de Zoonoses discorreu sobre o aumento da presença de artrópodos silvestres em bairros de Petrolina, destacando as espécies mais comuns na região, o que gerou indagações sobre as causas para o aumento de acidente e sobre as estratégias dos artrópodos para se adaptar ao ambiente doméstico. No PP da Equipe III, a bióloga da Univasf versou sobre os hábitos e modo de vida dos artrópodos, destacando sua importância para o equilíbrio ecológico. Os estudantes indagaram sobre: motivos para o aumento de acidentes por AP na região; qual a época do ano de maior frequência de acidentes; como os AP se alimentam e se reproduzem, entre outros aspectos.

As equipes IV e V realizaram entrevistas em duas comunidades da cidade, sendo 20 moradores da zona urbana (IV) e 20 da zona rural (V). Os moradores foram selecionados por meio de uma amostragem aleatória simples, entre os adultos presentes nas residências por ocasião da visita dos discentes e que aceitaram participar voluntariamente da pesquisa, após serem informados sobre os objetivos da pesquisa e assinarem os TCLI. Tanto na zona urbana quanto na rural, os entrevistados responderam sobre o contato com esses animais, se já tinham sofrido algum acidente e o que fizeram nessa situação, por quais sintomas foram acometidos e como eles se precaviam para evitar tais acidentes.

Os estudantes de todas as equipes participaram de forma dinâmica, realizaram perguntas contextualizadas e registraram as respostas dos profissionais e moradores para posterior análise. Houve certo desconforto no contato inicial com os entrevistados, devido à timidez dos estudantes no momento de realizar os questionamentos, o que foi superado ao longo do tempo devido à participação efetiva e espontânea do público alvo.

\subsection{ETAPA 5 - ELABORAÇÃO DO RELATÓRIO CIENTÍFICO}

Após a coleta de dados, os estudantes analisaram as variáveis mensuradas em seu PP, tais como: o número e a gravidade de acidentes no município, percepção dos moradores sobre os acidentes, medidas preventivas, cuidados pós-acidente e diversidade e ecologia de AP, entre outros. A produção do relatório científico fortaleceu a apresentação dos resultados e a construção de conclusões sobre a temática. Destaca-se que a produção de textos científicos pelos estudantes se configura como importante instrumento que favorece a aprendizagem e estimula o protagonismo.

Os relatórios evidenciaram de forma clara e objetiva as informações e resultados da pesquisa das cinco equipes. As equipes se esforçaram na produção dos seus textos pois todas obtiveram classificação "boa" ou "muito boa" (Quadro 2) na maioria dos critérios avaliados. 
Observamos ainda um crescimento nos textos finais produzidos pelas equipes I e II em relação aos planos de pesquisa. No critério de organização textual, os relatórios obtiveram classificação "boa" ou "muito boa", tendo sido escritos em linguagem clara e objetiva, em sequência lógica, com poucos erros de ortografia. Em relação à adequação à formatação, os textos também foram considerados "bons" ou "muito bons" porque atenderam a todas as normas acordadas previamente. No quesito Contextualização, obtiveram avaliação "boa" ou "muito boa", uma vez que relacionaram as informações obtidas na pesquisa com a temática trabalhada nas aulas e com a revisão bibliográfica realizada. Em relação à qualidade de recursos não textuais, todas as equipes obtiveram classificação "muito boa", visto que construíram gráficos ou tabelas para sintetizar os resultados obtidos nas entrevistas e na pesquisa documental.

\subsection{ETAPA 6 - SOCIALIZAÇÃO DO CONHECIMENTO}

Os trabalhos foram apresentados oralmente junto ao pôster na sala de aula, no contraturno, para que todos conhecessem (e aprendessem com) a pesquisa realizada pelos colegas. Após a bem sucedida apresentação, os alunos se motivaram a realizar uma exposição no pátio da escola, na qual apresentaram os pôsteres para outras turmas do ensino fundamental e médio. Ao fim da apresentação, distribuíram panfletos explicativos produzidos por eles, sobre artrópodos peçonhentos e medidas de prevenção contra acidentes.

Avaliamos as apresentações de acordo com os seguintes critérios: clareza, domínio do conteúdo, postura e organização do pôster (Quadro 2). De modo geral, as equipes receberam classificação "boa" ou "muito boa" em todos os critérios estabelecidos com exceção de uma equipe que apresentou dificuldades na clareza e na desenvoltura; no entanto, os integrantes demonstraram domínio do conteúdo e organização adequada do pôster.

A abordagem investigativa adotada nesta SEI mostrou-se eficiente na construção do conhecimento, uma vez que proporcionou a participação ativa dos estudantes no processo de aprendizagem. Nessa perspectiva, Zômpero e Laburú (2011) defendem que as atividades investigativas promovem a aprendizagem dos conteúdos conceituais e procedimentais, além de fortalecer habilidades cognitivas e a compreensão do conhecimento científico.

A intervenção abrangeu as etapas propostas por Parma, Brugnago e Bellucco (2018), que propõem que uma atividade didática investigativa seja desenhada numa sequência de fases que buscam o engajamento dos envolvidos; a exploração do conteúdo; a explicação dos problemas da pesquisa; a condução do estudo e a avaliação dos resultados. Na SEI descrita, o engajamento foi construído a partir da realidade dos estudantes, que se depararam com um 
problema local. Em seguida, os estudantes conheceram métodos de coleta, organização e apresentação dos dados buscando responder à pergunta motivadora; também mobilizaram conhecimentos teóricos da Biologia e os associaram a vivências humanas para a compreensão de cenários mais complexos - e aplicados - nos quais o conhecimento se insere. Dando continuidade, os estudantes prepararam e apresentaram seus relatos de forma escrita e oral, para discussão coletiva e comunicação com os colegas.

Ao longo de todas as etapas, priorizamos características do ensino por investigação, como descritas por Azevedo (2004): proposta do problema, levantamento de hipóteses, coleta de dados, análise dos dados obtidos e elaboração das conclusões. Dessa forma, os discentes foram desafiados a desenvolver múltiplas habilidades que os capacitam a resolver problemas relacionados ao seu cotidiano no contexto local. Scarpa e Campos (2018) argumentam que o ensino por investigação permite a construção de novos conhecimentos e habilidades pelos alunos, e afirmam que as características dessa abordagem possibilitam o desenvolvimento de um sujeito crítico, questionador e com grande capacidade argumentativa.

Um aspecto particularmente interessante na SEI foi a apropriação de conhecimentos práticos obtidos junto à comunidade externa, como biólogo, médico, oficial de bombeiros, veterinário, e, especialmente, a comunidade local. Os estudantes complementaram saberes e exerceram o senso crítico para discernir entre procedimentos "não-medicinais" pouco válidos, como o uso de preparos fitoterápicos, infusões, chás, rezas e aplicação de lâmina quente sobre o local da picada, uma prática mais comumente utilizada por pessoas idosas ou residentes da zona rural (LIMA; VASCONCELOS, 2006) de conhecimentos populares válidos, incluindo medidas empíricas de prevenção de acidentes, sob a ótica do respeito e da empatia.

Mudanças atitudinais também foram concretizadas. Por exemplo, a impressão negativa inicial manifestada pela opinião de $67,5 \%$ dos estudantes que afirmaram que matariam um animal peçonhento se o encontrasse, foi substituída por um entendimento do papel ecológico desses seres vivos. Os estudantes demonstraram ter elaborado relações de causa e efeito entre a urbanização e o favorecimento de algumas espécies, percebendo maior número de acidentes em bairros mais populosos. Para Freitas et al. (2006), a desorganizada ocupação urbana e as modificações do habitat podem ampliar o contato entre humanos e artrópodos peçonhentos, aumentando sua importância como problema de saúde pública.

De acordo com Parâmetros Curriculares para o Ensino Médio (PCNEM), o ensino deve prover ao educando a capacidade de formular questões, diagnosticar e propor soluções para 
problemas reais (BRASIL, 2018). A Base Nacional Comum Curricular (BRASIL, 2017) propõe dez competências gerais para o ensino básico, independentemente da série ou da disciplina específica. Podemos afirmar que algumas destas competências foram estimuladas - em diferentes níveis de profundidade - nesta Sequência de Ensino Investigativa (Quadro 3).

Quadro 3 - Exemplos de competências do ensino básico (BNCC) trabalhadas na SEI

\begin{tabular}{|c|c|}
\hline Competência & $\begin{array}{c}\text { Operacionalização/ } \\
\text { Estratégia de observação }\end{array}$ \\
\hline Conhecimento & $\begin{array}{l}\text { Os estudantes foram instigados a construir conhecimento com base em } \\
\text { pesquisa bibliográfica, documental e levantamento. A partir da experiência, } \\
\text { puderam elaborar modelos mentais propondo explicações cientificas sobre } \\
\text { acidentes causados por AP, visando entender e explicar a realidade }\end{array}$ \\
\hline $\begin{array}{l}\text { Pensamento científico, } \\
\text { crítico e criativo }\end{array}$ & $\begin{array}{l}\text { Os estudantes puderam formular problemas, construir hipóteses, desenhar } \\
\text { protocolos de coleta de dados, propor soluções em casos de acidentes e } \\
\text { estabelecer relações de causa-efeito, criando seus questionamentos } \\
\text { específicos para cada fonte externa de conhecimento }\end{array}$ \\
\hline Comunicação & $\begin{array}{l}\text { A SEI mobilizou competências de produção textual, em diversos formatos } \\
\text { para o compartilhamento de informaçôes, como relatórios científicos, e } \\
\text { também estimulou a oralidade na apresentação para os colegas da escola, } \\
\text { estimulando o diálogo entre os colegas }\end{array}$ \\
\hline $\begin{array}{l}\text { Trabalho e projeto de } \\
\text { vida }\end{array}$ & $\begin{array}{l}\text { A atividade estimulou a curiosidade por profissões nas áreas de ciências } \\
\text { médicas e biológicas, e dos agentes de proteção à população, aproximando os } \\
\text { estudantes da realidade do mundo do trabalho e estimulando a compreensão } \\
\text { de como o conhecimento teórico abordado na escola é apropriado no } \\
\text { desempenho profissional }\end{array}$ \\
\hline Argume & $\begin{array}{l}\text { Os estudantes criaram as situações clínicas, problematizam o conteúdo, } \\
\text { discutiram os temas geradores em grupo e argumentaram com base nos } \\
\text { resultados, respondendo aos questionamentos durante as apresentações }\end{array}$ \\
\hline $\begin{array}{l}\text { Autoconhecimento e } \\
\text { Autocuidado }\end{array}$ & $\begin{array}{l}\text { A aprendizagem foi sintonizada com a promoção da saúde e prevenção de } \\
\text { acidentes, esclarecendo sobre riscos e cuidados, identificando riscos e } \\
\text { sugerindo mudanças atitudinais }\end{array}$ \\
\hline Empatia e cooperação & $\begin{array}{l}\text { As etapas da SEI foram conduzidas de modo coletivo, dentro de cada equipe } \\
\text { e conjuntamente com toda a turma, sendo necessária a negociação e a } \\
\text { cooperação. Os estudantes direcionaram sua compreensão a profissionais e } \\
\text { habitantes do município, sob a ótica do respeito e da empatia }\end{array}$ \\
\hline $\begin{array}{l}\text { Responsabilidade e } \\
\text { Cidadania }\end{array}$ & $\begin{array}{l}\text { Os estudantes se sentiram responsáveis por compartilhar conhecimentos } \\
\text { cientificamente válidos, e associaram as informações com sua vida cidadã } \\
\text { (tratamento de acidentes, por exemplo), habilitando-se a atuar como agentes } \\
\text { multiplicadores de conhecimento }\end{array}$ \\
\hline
\end{tabular}

A autonomia e o protagonismo foram manifestados ao longo do interesse e engajamento dos estudantes na pesquisa, na escolha do tema, na elaboração das perguntas, na produção autoral e na socialização dos conhecimentos. A formulação de hipóteses norteou as atividades, pois os estudantes necessitaram identificar os AP mais frequentemente envolvidos em acidentes em Petrolina, bem como buscaram solucionar dúvidas como: a relação entre o crescimento da população urbana, a modificação ambiental (por exemplo, substituição da Caatinga nativa por edificações) e o aumento dos casos, e a importância dos artrópodos no equilíbrio ecológico, entre outros. 
O envolvimento dos estudantes foi observado na participação individual e em grupo, manifestado nos relatos escritos no diário de bordo, em que puderam registrar suas impressões e dúvidas, como também avaliar o desempenho individual e da equipe. Para Oliveira, Gerevini e Strohschoen (2017), o diário de bordo configura-se como importante instrumento de acompanhamento dos projetos científicos desenvolvidos pelos discentes e contribui no processo de alfabetização científica. Em respeito à contribuição individual, e ao amadurecimento do senso de trabalho em equipe, optamos, como um exercício de reflexão, por não corrigir os diários de bordo, sugerindo que as próprias equipes avaliassem seu próprio desenvolvimento e colaboração. No diário, as equipes registraram positivamente a experiência vivenciada, destacando como pontos principais o fato de interagirem com a comunidade externa; a sensação de atuarem como cientistas; e a aplicabilidade de suas próprias descobertas.

No ensino por investigação, a discussão e a análise dos dados a partir de critérios científicos, aproximam o estudante da prática profissional, da mesma forma que auxiliam a prepará-lo para um mundo baseado em argumentações, debates e conflitos de ideias. O uso da linguagem acadêmica na produção de textos científicos é imprescindível para o desenvolvimento de habilidades de síntese e aperfeiçoamento de ideias de Carvalho (2004). Além disso, a redação de textos científicos requer linguagem objetiva, clara, coesa e concisa, e as ideias devem ser apresentadas sem ambiguidades, com um vocabulário adequado (BARRENECHEA, 2016).

A interdisciplinaridade foi estimulada, uma vez que os estudantes se apropriaram do uso de regras formais da Língua Portuguesa, bem como de ferramentas da Matemática, para apresentação dos resultados, com textos gramaticalmente corretos, e tabelas e gráficos quantitativos. Por fim, a socialização dos resultados deslocou o foco do professor - como costuma ser na abordagem convencional - para o estudante, que assumiu a responsabilidade (e o risco) de expor informações cientificamente válidas - algumas das quais geradas pelas próprias equipes.

A SEI aproximou os estudantes da realidade profissional de oficiais do corpo de bombeiros, pesquisadores, médicos e biólogos, oferecendo um vislumbre de oportunidades de trabalho relacionadas à aplicação do conteúdo biológico. O conhecimento contribuiu, ainda, para reforçar o senso de autocuidado, da promoção da saúde, da cooperação e da empatia provocando no estudante o olhar respeitoso para com a população e os profissionais (Quadro 
3). Durante a exposição dos pôsteres, alguns estudantes expressaram o interesse em seguir carreiras nas áreas de Ciências Biológicas e da Saúde.

Apesar do resultado exitoso, é importante explicitar algumas dificuldades da intervenção, as quais precisam ser consideradas pelo docente. Antes de participar da proposta, os estudantes possuíam limitada experiência formal com o método científico e com a produção de projetos e relatórios científicos, o que exigiu especial atenção da docente no estímulo à leitura de textos científicos. A docente também foi desafiada a apropriar-se de um arcabouço teórico e metodológico sobre pesquisa científica, construído principalmente ao longo de sua formação no Mestrado Profissional em Ensino de Biologia do Centro Acadêmico de Vitória da Universidade Federal de Pernambuco. A construção e validação desta SEI é o produto principal de sua dissertação.

A SEI exigiu um tempo considerável, e, refletimos que algumas etapas, especialmente as iniciais, poderiam ser executadas em menor tempo. O limitado acesso à internet comprometeu parte da pesquisa bibliográfica, e foi necessária a articulação para garantir o transporte seguro dos jovens às instituições e para os bairros. A docente buscou "otimizar" o tempo investido na atividade com a incorporação de conteúdos de Taxonomia, Ecologia, Zoologia, Conservação, Imunologia, e, naturalmente, Saúde.

Ainda assim, a SEI mostrou-se simples e enriquecedora mesmo diante de um contexto e infraestrutura precários (ausência de laboratório na escola, acesso limitado a internet). Ao fazer uso de ferramentas acessíveis, como materiais disponíveis na internet e palestras com profissionais locais, o docente pôde explorar possibilidades didáticas, sem acarretar custos para a gestão escolar. Para garantir a segurança, nenhum estudante foi exposto a artrópodos vivos.

\section{CONSIDERAÇÕES FINAIS SOBRE A INTERVENÇÃO DIDÁTICA}

A educação científica possibilita ao indivíduo analisar situações cotidianas, compreender problemas e tomar decisões considerando conhecimentos técnico-científicos. Isso requer tanto a compreensão de teorias das várias disciplinas científicas quanto o conhecimento sobre suas formas de produzir afirmações, testar hipóteses e usar evidências e justificativas; requer as relações entre a ciência, a tecnologia e a sociedade (TRIVELATO; TONIDANDEL, 2015). Portanto, a estratégia pedagógica do ensino por investigação permite familiarizar os alunos com as etapas do método científico que tem como objetivo propor a resolução de questões a partir da investigação e estimular a produção científica. 
Segundo Demo (2004), o emocionante da pesquisa científica está na construção de novo conhecimento, e esta emoção pôde ser observada nos registros feitos pelos estudantes no decorrer dessa experiência, que compartilharam uma mistura de sentimentos como ansiedade, expectativa e satisfação. Para Gillies e Nichols (2014, p.13)

\footnotetext{
Na verdade, este é o desafio do ensino da ciência da investigação - como ensiná-la de forma que o interesse dos alunos seja capturado de forma que eles fiquem entusiasmados com os fenômenos sob investigação e estejam dispostos a trabalhar com outros para explorar suas ideias e desenvolver as estratégias necessárias para comunicar suas perspectivas e entendimentos.
}

Concluímos que, apesar de dificuldades no percurso, a sequência de ensino baseada em investigação científica, além de construir conhecimento sobre artrópodos peçonhentos, aguçou o pensamento crítico dos aprendizes no sentido de buscar conhecimento por meio da prática e pesquisas científicas. A docente também fortaleceu suas competências de pesquisa, tornandose, também, uma aprendiz, formulando, testando e validando objetivos, processos e indicadores de cumprimento de cada etapa da SEI. Podemos, ainda, afirmar que esta sequência pode ser moldada para outras realidades escolares, inclusive para outros temas das Ciências.

\section{REFERÊNCIAS}

AZEVEDO, Maria Cristina P. S. Ensino por investigação: problematizando as atividades em sala de aula. In CARVALHO, Anna Maria Pessoa de (Org) Ensino de ciências: unindo a pesquisa e a prática. São Paulo. Pioneira Thomson, 2004.

BARRENECHEA, Cristina A. Redação científica com o uso de ferramentas tecnológicas. Curitiba-PR: Setor de Educação, 2016.

BEHRENS, Marilda A. Projetos de aprendizagem colaborativa num paradigma emergente. In: MORAN, José M.; MASETTO, Marcos T.; BEHRENS, Marilda A. Novas tecnologias e mediação pedagógica. Campinas, SP: Papirus, 2000, p. 67-132.

BOROCHOVICIUS, Eli; TORTELLA, Jussara C. B. Aprendizagem Baseada em Problemas: um método de ensino-aprendizagem e suas práticas educativas. Ensaio: Avaliação e Políticas Públicas em Educação, v. 22, n. 83, p. 263-294, 2014.

BRASIL. Ministério da Educação. Base Nacional Comum Curricular. Ministério da Educação, Brasília, DF: MEC, 2017. Disponível em:

http://basenacionalcomum.mec.gov.br/images/BNCC_publicacao.pdf. Acesso em: 10 fev 2020 .

BRASIL. Ministério da Educação. Parâmetros Curriculares Nacionais para o Ensino Médio (PCNEM), 2018. p. 1-141.

BRASIL. Ministério da Saúde. Acidentes por animais peçonhentos: o que fazer e como evitar. Ministério da Saúde, 2020. Disponível em: http://www.saude.gov.br/saude-de-az/acidentes-por-animais-peconhentos. Acesso: 10 jun 2020. 
CARVAlHO, Anna Maria P. de. O Ensino de Ciências: Unindo a Pesquisa e a Prática. São Paulo. Cengage Learning, 2004.

CARVALHO, Anna Maria P. de. O ensino de ciências e a proposição de sequências de ensino investigativas. In: CARVALHO, Anna Maria P. de (Org.). Ensino de ciências por investigação: condições para implementação em sala de aula. São Paulo: Cengage Learning, 2013. p. 1-20.

COSTA JUNIOR, Paulo Herton. O conteúdo decomposição no ensino médio: Análise do livro didático e de uma atividade experimental. 2019. 120 f. Dissertação (Mestrado Profissional em Ensino de Biologia) Universidade Federal de Pernambuco, Vitória de Santo Antão, 2019.

DEMO, Pedro. Universidade, Aprendizagem e Avaliação: Horizontes Reconstrutivos. Porto Alegre: Mediação, 2004.

FREITAS, Gilson C. C.; OLIVEIRA, Américo E.; FARIAS, J. E. B; VASCONCELOS, Simão D. Acidentes por aranhas, insetos e centopéias registrados no centro de assistência toxicológica de Pernambuco (1993 a 2003), Revista de Patologia Tropical, v. 35, n. 2, p. 148-156, 2006.

GILLIES, Robyn M.; NICHOLS, Kim. How to support primary teachers' implementation of inquiry: Teachers' reflections on teaching cooperative inquiry-based science. Research in Science Education, v. 45, n. 2, 2014. http://doi.org/10.1007/s11165-014-9418-X

GONÇALVES, Adair; BARROS, Eliana. Planejamento sequenciado da aprendizagem: modelos e sequências didáticas. Revista Linguagem \& Ensino, v. 13, n. 1, p. 37-69, 2010.

GRAY, David. Pesquisa no Mundo Real. Porto Alegre, Artmed, 2012.

KRASILCHIK, Myriam. Prática de ensino de biologia. $4^{\circ}$ ed. São Paulo: Edusp, 2005.

LIMA, Kênio E. C.; VASCONCELOS, Simão D. Acidentes com animais peçonhentos: um estudo etnozoológico com agricultores de Tacaratu, sertão de Pernambuco. Sitientibus Série Ciências Biológicas, vol. 6, n. 2, p. 138-144, 2006.

OLIVEIRA, Aldeni; GEREVINI, Alessandra; STROHSCHOEN, Andreia. Diário de Bordo: uma ferramenta metodológica para o desenvolvimento da Alfabetização Científica. Revista Tempos e Espaços em Educação, 2017. https://doi.org/10.119.10.20952/revtee.v10i22.6429

PARMA, Marivaldo; BRUGNAGO, Eduardo L.; BELLUCCO, Alex. Replanejando uma sequência de ensino investigativa sobre conservação da energia. Experiências em Ensino de Ciências, v. 13, n. 5, p. 92-114, 2018.

REHOREK, Susan J. Inquiry-Based Teaching. The American Biology Teacher, v. 66, n. 7, p. 493-499, 2004.

SASSERON, Lucia H.; CARVALHO, Anna Maria P. de. Almejando a Alfabetização Científica no ensino fundamental: a proposição e a procura de indicadores do processo. Investigações em Ensino de Ciências, v.13, n.3, p.333-352, 2008. 
SCARPA, Daniela L.; CAMPOS, Natália F. Potencialidades do ensino de Biologia por Investigação. Estudos Avançados, v. 32, n. 94, p. 25-42, 2018.

SINGER, Helena. Pelo protagonismo de estudantes, educadores e escolas. In: LOVATO, Antonio; YIRULA, Carolina P.; FRANZIM, Raquel (Org.). Protagonismo: A potência de ação da comunidade escolar. São Paulo-SP: Ashoka/Alana, 2017, p. 14-21.

SLONGO, Iône I. P.; DELIZOICOV, Demétrio. Um panorama da produção acadêmica em ensino de biologia desenvolvida em programas nacionais de pós-graduação. Investigações em Ensino de Ciências, v. 11, n. 3, p. 323-341, 2006.

TRIVELATO, Silvia L. F.; TONIDANDEL, Sandra M. R. Ensino por investigação: eixos organizadores para sequências de ensino de Biologia. Ensaio Pesquisa em Educação em Ciências, v. 17, p. 97-114, 2015.

ULLA, Mark B. Benefits and challenges of doing research: Experiences from Philippine public school teachers. Issues in Educational Research, v. 28, n. 3, 797-810, 2018.

VASCONCELOS, Simão D.; LIMA, Kênio E. C. Concepções de Professores da Rede Pública de Pernambuco sobre Feiras de Ciências: Reflexões a partir de uma Atividade Lúdica. Revista Brasileira de Ensino de Ciências e Matemática, v. 3, n. 2, p. 488-518, 2020.

ZABALLA, Antoni. A prática educativa: como ensinar. Porto Alegre: Artmed, 1998.

ZÔMPERO, Andreia F.; LABURÚ, Carlos E. Atividades investigativas no ensino de Ciências: Aspectos históricos e diferentes abordagens. Ensaio Pesquisa em Educaçãa em Ciência, v. 13, n. 3, p. $67-80,2011$.

\section{Agradecimentos}

Prestamos uma homenagem à primeira autora, vítima da pandemia da covid-19 no exercício de sua profissão, uma professora que dedicou sua vida a uma docência questionadora, transformadora e investigativa. Agradecemos aos profissionais especializados e aos habitantes de Petrolina que gentilmente participaram da nossa pesquisa, compartilhando seus saberes com os estudantes, à Coordenação de Aperfeiçoamento de Pessoal de Ensino Superior (Capes) pelo financiamento do Mestrado Profissional em Ensino de Biologia (Profbio), aos Profs. Kênio Lima, Carlos Albuquerque e Polyana Nascimento pela leitura crítica do manuscrito, e aos estudantes que participaram espontaneamente e entusiasmadamente desta atividade. A pesquisa foi aprovada pelo Comitê de Ética (CAAE $n^{\circ}$ 19750419.1.0000.9430) e os estudantes tiveram o consentimento dos responsáveis para a participação e desenvolvimento da pesquisa. $\mathrm{O}$ segundo autor é Bolsista de Produtividade do Conselho Nacional de Desenvolvimento Científico e Tecnológico (CNPq). 
Apêndice A. Fontes de informação sugeridas e disponibilizadas para os estudantes

\begin{tabular}{|c|c|c|}
\hline Texto & Autor/Instituição/Portal & Descrição \\
\hline $\begin{array}{l}\text { Guia de Bolso } \\
\text { - Animais } \\
\text { Peçonhentos }\end{array}$ & $\begin{array}{l}\text { Fundação Ezequiel Dias - FUNED } \\
\text { (http://vigilancia.saude.mg.gov.br/index.php/d } \\
\underline{\text { ownload/guia-de-bolso-animais-peconhentos- }} \\
\underline{\text { funed/) }}\end{array}$ & $\begin{array}{l}\text { Informações sobre animais peçonhentos } \\
\text { que facilitam o reconhecimento das } \\
\text { espécies mais frequentemente encontradas } \\
\text { em residências, a história natural das } \\
\text { espécies e medidas de primeiros socorros } \\
\text { em caso de acidentes. }\end{array}$ \\
\hline $\begin{array}{l}\text { Animais } \\
\text { peçonhentos e } \\
\text { venenosos }\end{array}$ & $\begin{array}{l}\text { Portal Educação } \\
\text { (https://siteantigo.portaleducacao.com.br/conte } \\
\text { udo/artigos/enfermagem/animais- } \\
\text { peconhentos-e-venenosos/891) }\end{array}$ & $\begin{array}{l}\text { O texto traz informações sobre animais } \\
\text { venenosos e peçonhentos, tratamento no } \\
\text { caso de acidentes e medidas preventivas. }\end{array}$ \\
\hline $\begin{array}{l}\text { Acidentes por } \\
\text { animais } \\
\text { peçonhentos: } \\
\text { o que fazer e } \\
\text { como evitar }\end{array}$ & $\begin{array}{l}\text { Portal do Ministério da Saúde } \\
\text { (http://www.saude.gov.br/saude-de-a- } \\
\text { z/acidentes-por-animais-peconhentos) }\end{array}$ & $\begin{array}{l}\text { O texto apresenta informações sobre } \\
\text { acidentes causados por animais } \\
\text { peçonhentos e formas de evitar esses } \\
\text { acidentes. }\end{array}$ \\
\hline $\begin{array}{l}\text { Recursos } \\
\text { audiovisuais } \\
\text { sobre o tema } \\
\text { artrópodos } \\
\text { peçonhentos }\end{array}$ & $\begin{array}{l}\text { Rosa Pavone Pimonti e Sílvia Lucas } \\
\text { (https://bibliotecadigital.butantan.gov.br/arqui } \\
\underline{\text { vos/53/PDF/18.pdf) }}\end{array}$ & $\begin{array}{l}\text { Artigo versa sobre os artrópodos } \\
\text { peçonhentos e produção de recursos } \\
\text { audiovisuais sobre o conteúdo para serem } \\
\text { utilizados nas escolas. }\end{array}$ \\
\hline Abelhas & $\begin{array}{l}\text { FIOCRUZ } \\
\text { (http://www.fiocruz.br/biosseguranca/Bis/infa } \\
\text { ntil/abelhas.htm e } \\
\text { http://www.fiocruz.br/biosseguranca/Bis/virtu } \\
\text { al\%20tour/hipertextos/up2/abelhas.html) }\end{array}$ & $\begin{array}{l}\text { Texto sobre a vida, importância e tipos de } \\
\text { abelhas mais comuns no Brasil. }\end{array}$ \\
\hline $\begin{array}{l}\text { Conhecendo } \\
\text { as abelhas: um } \\
\text { projeto de } \\
\text { ensino }\end{array}$ & $\begin{array}{l}\text { Natália de Paula Sá e Mauro Prato } \\
\text { (https://www.researchgate.net/publication/277 } \\
\underline{052730 \_ \text {Conhecendo_as_abelhas_um_projeto }} \\
\text { de ensino) }\end{array}$ & $\begin{array}{l}\text { Trabalho sobre a diversidade das abelhas } \\
\text { no Brasil }\end{array}$ \\
\hline $\begin{array}{l}\text { Artrópodes e } \\
\text { relações com } \\
\text { os demais } \\
\text { seres vivos: } \\
\text { contribuições } \\
\text { para o ensino } \\
\text { médio. }\end{array}$ & $\begin{array}{l}\text { Kátia Valéria Wanderley de Sousa Silva } \\
\text { (http://www.editorarealize.com.br/revistas/con } \\
\text { edu/trabalhos/TRABALHO_EV117_MD4_S } \\
\underline{\text { A16_ID10095_17092018090454.pdf) }}\end{array}$ & $\begin{array}{l}\text { Trabalho sobre artrópodos e proposta de } \\
\text { ensino sobre os mesmos }\end{array}$ \\
\hline
\end{tabular}


Apêndice B. Orientações para o Plano de Pesquisa e para o Relatório Científico

\begin{tabular}{|c|c|}
\hline & Elaboração do Plano de Pesquisa \\
\hline & Título do Trabalho \\
\hline & Identificação da escola, dos alunos, do professor orientador \\
\hline & Questão ou problema de pesquisa \\
\hline & $\begin{array}{l}\text { A partir de uma pequena introdução sobre o tema, devemos fazer uma descrição clara da questão (problema) a } \\
\text { ser investigada. Neste item você deve responder a pelo menos uma das questões abaixo: } \\
\text { - Qual é seu objetivo? } \\
\text { - Qual pergunta científica você está tentando responder? } \\
\text { - Quais problemas de sua comunidade sua pesquisa pode ajudar a entender? } \\
\text {. Defina e descreva o problema escolhido. }\end{array}$ \\
\hline & Objetivo \\
\hline & $\begin{array}{l}\text { Nesse item devemos explicar, de maneira clara, o que pretendemos atingir com a investigação, aonde } \\
\text { pretendemos chegar com esse trabalho, quais contribuições queremos que ele traga. O Objetivo do Projeto } \\
\text { deve descrever de forma geral: } \\
\text { - Onde pretendemos chegar com esse trabalho. } \\
\text {. Quais contribuições queremos que ele traga. }\end{array}$ \\
\hline & Materiais e Métodos (Procedimentos) que serão utilizados \\
\hline & $\begin{array}{l}\text { Nesse item devemos escrever onde e como será conduzida a pesquisa, as variáveis que serão estudadas, os } \\
\text { métodos que serão adotados para coletar as informações e os procedimentos e testes que serão adotados. } \\
\text { Explicar como será executada a sua pesquisa ou experimento e como irá testar sua hipótese. } \\
\text { - Especificar como as medidas dos resultados vão provar ou refutar sua hipótese. } \\
\text { · Liste os materiais e os equipamentos que serão utilizados. } \\
\text {. Liste soluções ao seu problema e detalhe o que você fará para chegar a esta solução. }\end{array}$ \\
\hline & Referências \\
\hline & $\begin{array}{l}\text { Listagem dos trabalhos e autores consultados na execução do projeto. Incluir livros, revistas, jornais e / ou } \\
\text { sites consultados. } \\
\text { - Ao citar revistas, jornais citar a data da publicação. } \\
\text { - Ao fazer referência à sites de internet, incluir sempre o endereço completo da página visitada e data da } \\
\text { consulta. }\end{array}$ \\
\hline & Estrutura do Relatório Científico \\
\hline & Elementos pré-textuais \\
\hline & $\begin{array}{l}\text { Capa } \\
\text { Folha de Rosto } \\
\text { Agradecimentos } \\
\text { Resumo } \\
\text { Sumário }\end{array}$ \\
\hline & Elementos textuais \\
\hline & $\begin{array}{l}\text { Introdução } \\
\text { Objetivos } \\
\text { Metodologia } \\
\text { Apresentação e discussão dos resultados } \\
\text { Conclusões }\end{array}$ \\
\hline & Elementos pós-textuais \\
\hline & $\begin{array}{l}\text { Referências bibliográficas } \\
\text { Anexos } \\
\text { Apêndices }\end{array}$ \\
\hline & Formatação \\
\hline
\end{tabular}


Apêndice C: Aspectos avaliativos do plano de pesquisa, do relatório científico e da apresentação do poster (Adaptado de COSTA JUNIOR, 2019)

\begin{tabular}{|c|c|c|c|}
\hline \multicolumn{4}{|c|}{ Critérios de avaliação do Plano de Pesquisa } \\
\hline Critério & Regular & Bom & Muito Bom \\
\hline Organização textual & $\begin{array}{l}\text { Texto mal organizado } \\
\text { com muitos erros } \\
\text { ortográficos. }\end{array}$ & $\begin{array}{l}\text { Texto bem escrito e } \\
\text { organizado, com falhas } \\
\text { na sequência e com } \\
\text { alguns erros ortográficos. }\end{array}$ & $\begin{array}{l}\text { Texto conciso, e objetivo, } \\
\text { bem redigido e com } \\
\text { poucos erros ortográficos. }\end{array}$ \\
\hline $\begin{array}{l}\text { Adequação às normas } \\
\text { de produção textual }\end{array}$ & $\begin{array}{l}\text { O texto atendeu a } \\
\text { menos de } 50 \% \text { das } \\
\text { normas propostas. }\end{array}$ & $\begin{array}{l}\text { O texto atendeu de } 50 \% \\
\text { a menos de } 75 \% \text { das } \\
\text { normas propostas. }\end{array}$ & $\begin{array}{l}\text { Mais de } 75 \% \text { das normas } \\
\text { propostas foram atendidas } \\
\text { no texto. }\end{array}$ \\
\hline Contextualização & $\begin{array}{l}\text { Conteúdos abordados } \\
\text { de forma superficial, } \\
\text { mal relacionados ao } \\
\text { tema trabalhado. }\end{array}$ & $\begin{array}{l}\text { Conteúdos abordados de } \\
\text { forma adequada, bem } \\
\text { relacionados ao tema } \\
\text { trabalhado. }\end{array}$ & $\begin{array}{l}\text { Conteúdos abordados de } \\
\text { forma adequada, } \\
\text { totalmente relacionados ao } \\
\text { tema trabalhado. }\end{array}$ \\
\hline \multicolumn{4}{|c|}{ Critérios de avaliação do Relatório Científico } \\
\hline Organização textual & Ver acima & Ver acima & Ver acima \\
\hline $\begin{array}{l}\text { Adequação às normas } \\
\text { de produção textual }\end{array}$ & Ver acima & Ver acima & Ver acima \\
\hline Contextualização & Ver acima & Ver acima & Ver acima \\
\hline $\begin{array}{l}\text { Qualidade de Figuras } \\
\text { e Tabelas }\end{array}$ & $\begin{array}{l}\text { Imagens com má } \\
\text { qualidade, pouco } \\
\text { relacionadas ao tema, } \\
\text { presença de tabelas e } \\
\text { gráficos com dados } \\
\text { incorretos. }\end{array}$ & $\begin{array}{l}\text { Imagens com boa } \\
\text { qualidade, relacionadas } \\
\text { ao tema, presença de } \\
\text { tabelas e gráficos com } \\
\text { alguns dados incorretos. }\end{array}$ & $\begin{array}{l}\text { Imagens com ótima } \\
\text { qualidade, relacionadas ao } \\
\text { tema, presença de tabelas e } \\
\text { gráficos com dados } \\
\text { precisos. }\end{array}$ \\
\hline \multicolumn{4}{|c|}{ Critérios de avaliação da apresentação dos pôsteres } \\
\hline Clareza & $\begin{array}{l}\text { Apresentação de } \\
\text { forma confusa os } \\
\text { objetivos, etapas, } \\
\text { procedimentos e } \\
\text { conclusões do } \\
\text { projeto, pouca } \\
\text { coerência }\end{array}$ & $\begin{array}{l}\text { Apresentação de forma } \\
\text { concisa dos objetivos, } \\
\text { etapas, procedimentos e } \\
\text { conclusões do projeto, } \\
\text { boa coerência }\end{array}$ & $\begin{array}{l}\text { Apresentação de forma } \\
\text { concisa dos objetivos, } \\
\text { etapas, procedimentos e } \\
\text { conclusões do projeto, } \\
\text { ótima coerência }\end{array}$ \\
\hline Domínio do conteúdo & $\begin{array}{l}\text { Apresenta pouco } \\
\text { domínio de conteúdo } \\
\text { e segurança. }\end{array}$ & $\begin{array}{l}\text { Apresenta domínio de } \\
\text { conteúdo e segurança. }\end{array}$ & $\begin{array}{l}\text { Apresenta total domínio de } \\
\text { conteúdo e segurança. }\end{array}$ \\
\hline Postura & $\begin{array}{l}\text { Postura pouco } \\
\text { adequada, limitada } \\
\text { desenvoltura na } \\
\text { apresentação oral } \\
\end{array}$ & $\begin{array}{l}\text { Boa postura na } \\
\text { apresentação e boa } \\
\text { desenvoltura na } \\
\text { apresentação oral. }\end{array}$ & $\begin{array}{l}\text { Ótima postura na } \\
\text { apresentação e total } \\
\text { desenvoltura na } \\
\text { apresentação oral. }\end{array}$ \\
\hline $\begin{array}{l}\text { Organização do } \\
\text { pôster }\end{array}$ & $\begin{array}{l}\text { Pôster mal } \\
\text { organizado, sem } \\
\text { clareza e pouco } \\
\text { atraente visualmente. }\end{array}$ & $\begin{array}{l}\text { Pôster organizado, claro } \\
\text { e objetivo e atraente } \\
\text { visualmente. }\end{array}$ & $\begin{array}{l}\text { Pôster bem organizado, } \\
\text { claro e objetivo e atraente } \\
\text { visualmente. }\end{array}$ \\
\hline
\end{tabular}

